experience at IV administration. Perhaps we are unusual in that so many of our nurses do so many procedures.

Do any readers know of anyone else who is struggling with this issue? I have talked to one or two colleagues who were totally unaware of this guidance but I thought some of the Journal's readers might be.

Barbara Hollingworth, FFSRH, DRCOG Consultant in Family Planning and Sexual Health, Barking, Havering and Redbridge University Hospitals NHS Trust, UK.

E-mail:bah@lupins.plus.com

References

Mehigan S, Moore W, Hayes L. Nurse training in exual and reproductive health. J Fam Plann Reprod sexual and reproductive heatt

2 Faculty of Sexual and Reproductive Healthcare. Service Service Standards for Resuscilation in Sexual Healh Services. July 2006. hittp:/www.tsrh.org/admin/

3 Royal College of Nursing (RCN) Statement.

\section{Nurse training and the need for IUD fitters to have expertise in resuscitation}

I felt I had to put fingers to keyboard after reading the thoughtful Personal View by Shelley Mehigan and her colleagues ${ }^{1}$ along with the subsequent correspondence in the April 2010 issue of the Journal.

Nurse training in our specialty needs a nationally recognised and standardised educational pathway ${ }^{2}$ producing health care professionals who are 'fit for purpose'. This training must be theoretically and practically robust, be based on sound evidence and the accreditation must not be overly expensive. Our services may still be 'doctor-led' in many parts of the UK, but clinics would come to a grinding halt if nurses are restricted in their practice and become 'handmaidens' once more. The letter written by $\mathrm{Dr}$ Barbara Hollingworth ${ }^{3}$ clearly illustrates this point.

We have also had local community nursebased clinics fitting intrauterine contraceptives in general practice premises suspended because 'doctor cover' by the general practitioners [who can administer intravenous (IV) drugs] has been withdrawn. Faculty guidance in Service Standards for Resuscitation ${ }^{4}$ and Intrauterine Contraception ${ }^{5}$ does not clearly state that a health care professional proficient in giving IV drugs is available on site but this is implied by having atropine $(0.6 \mathrm{mg} / \mathrm{ml})$ available for IV use. Clinical Leads should check with their local Ambulance Trusts as many suggest that adrenaline is the only drug that needs to be available within community clinics.

I have recently asked over 70 health care professionals who fit intrauterine contraceptives about their use of atropine and no one has administered it. I have on one occasion in the last 22 years when a woman was very keen to keep an intrauterine device (IUD) in situ as she felt it was her only contraceptive option. On all other occasions when faced with vasovagal attacks or persistent bradycardias women have recovered by applying basic life support measures including the removal of the IUD device where necessary.

Perhaps when both these documents ${ }^{4,5}$ are reviewed this issue will be clarified.

Diana Mansour, FRCOG, FFSRH

Clinical Director, Sexual Health Services, NHS

Newcastle and North Tyneside, Community

Health, Newcastle upon Tyne, UK.

E-mail:Diana.Mansour@newcastle-pct.nhs.uk

References

1 Mehigan S, Moore W, Hayes L. Nurse training in sexual and reproductive health. J Fam Plann Reprod Health Care 2010; 36: 5-6.

2 Mehigan S, Moore W. Authors' response to correspondence about Nurse Training in SRH (Letter). J Fam Plann Reprod Health Care 2010; 36: 111.

3 Hollingworth B. Need for IUD fitters to have expertise in resuscitation (Letter). J Fam Plann Reprod Health Care 2010; 36: 179-180.

4 Faculty of Sexual and Reproductive Health Care. Service Standards for Resuscitation in Sexual Health Services. July 2006. http://www.ffprhc.org.uk/admin/ uploads/ServiceStandardsResuscitationSHServices. pdf [Accessed 9 May 2010]

5 Faculty of Sexual and Reproductive Health Care Clinical Guidance. Clinical Effectiveness Unit. Intrauterine Contraception. November 2007. http://www.ffprhc.org.uk/admin/uploads/CEUGuidance IntrauterineContraceptionNov07.pdf [Accessed 9 May 2010].

\section{Reply}

I would like to thank Drs Hollingworth and Mansour for their letters about nurse training and the need for intrauterine device (IUD) fitters to have expertise in resuscitation.1,2 This is a question that I am being increasingly asked by clinicians around the country as they become aware of the implications of recent guidance on this topic. Not only is it unrealistic to expect al the clinicians involved to undertake the extra training and regular practice to comply with the guidance - looking at the British Resuscitation Council guidelines, ${ }^{3}$ doing what is advised would need advanced life support (ALS)-level training with regular practice of the techniques - it also has implications for how services can be delivered not just by nurses but by doctors too. Many services will feel it is unworkable. Those that have tried, like Dr Hollingworth, to ask the Royal College of Nurses (RCN), have been referred to the Faculty guidance, ${ }^{4}$ and the Faculty rightly feel that they were following advice from the RCN.

As I understand it, the original guidance from the RCN, 5 which was directed at nurse fitting devices rather than assisting other clinicians and was based on discussions with the RCN legal team, advised that nurses should make a local risk assessment based on how often they felt a problem might arise? Would we insist on the same restrictions for doctors fitting an IUD/implant?

Why might we treat nurses differently?

Issues to consider include:

- Should the nurse fit an IUD very late in the evening?

- If the woman has had a difficult fitting in the past?

- Is there a need to have another registered practitioner (nurse or doctor) in clinic?

- If a woman had rushed in and had not eaten for hours, and so on?

Perhaps the way forward would be for one or more groups at the Faculty to produce guidance for use by all clinicians to follow in such scenarios. This would reflect the multidisciplinary aspect of the work and recognise that this could apply to either doctors or nurses, both groups having highlighted that this is an area where few currently feel able to undertake the actions suggested in the current guidance. If this guidance could be produced following discussion with experts in the field of resuscitation it would then hopefully be realistic, as well as being practical, and would reflect current evidence-based best practice.

\section{Shelley Mehigan, RGN}

Nurse Specialist (Contraception), Berkshire East Community Health Services, Sexual Health, Upton Hospital, Slough, UK.

E-mail: shelley.mehigan@berkshire.nhs.uk

1 Hollingworth B. Need for IUD fitters to have expertise Care 2010; 36: 179-180.

2 Mansour D. Nurse training and the need for IUD fitters to have expertise in resuscitation (Letter). J Fam Plann Reprod Health Care 2010; 36: 180 .

British Resuscitation Council guidelines.

4 Faculty of Sexual and Reproductive Health Care. Service Standards for Resuscitation in Sexual Health
Services. July 2006. http://www.ffprhc.org.uk/admin/ uploads/ServiceStandardsResuscitationSHServices. pdf [Accessed 9 May 2010]

5 Royal College of Nursing (RCN) Statement.

\section{Safe sex during pregnancy}

As a consultant in genitourinary medicine, I wish to comment on Box 1 entitled 'Is it safe to have sex? in Susan Quilliam's Consumer Correspondent $\operatorname{article}^{1}$ in the April issue of the Journal.

The second point made is that "if either partner has a sexually transmitted infection (STI), they should use protection ...". If one of a couple has an STI then is it generally recommended that for a treatable infection a couple desist completely from having any penetrative sex until treatment of both partners is complete. Condoms do not provide $100 \%$ protection against any STI and any untreated infections in pregnancy can carry serious consequences.

I am uncertain why protected anal sex should be "avoided altogether". If the couple exercises good hygiene practice is there any other concern about such a practice in regard to pregnancy? I could not find anything in the article to explain this advice.

Susan Young, FRCPI, FRCP

Consultant in Genitourinary Medicine, Sherwood Forest Hospitals NHS Foundation Trust, King's Mill Hospital, Sutton in Ashfield, UK.E-mail: Susan.Young@sfh-tr.nhs.uk

Reference

Quilliam S. Sex during pregnancy: Yes, Yes, Yes J Fam Plann Reprod Health Care 2010; 36: 97-98.

\section{Reply}

First, I wish to thank Dr Young for reading my article $^{1}$ so carefully and responding to it so thoughtfully in her letter. ${ }^{2}$

Dr Young is, of course, correct that if either partner in a couple has a sexually transmitted infection (STI) they should ideally not have sex at all until after treatment. However, in practice this advice is frequently ignored - particularly during pregnancy when partners want to reinforce their bond and reflect their closeness - so I was being pragmatic in advising protection.

Similarly, Dr Young is correct in saying that in ideal circumstances, anal sex is safe. But in the 'real life' situations that I hear about, hygiene practices around anal sex are often far from perfect and so, again pragmatically, during pregnancy in particular I generally advise avoidance.

Finally, the aim of my article, and the substance of the main body of my text, was to promote sex in pregnancy and ask professionals to encourage it. I didn't aim to give detailed information about risks - such information is covered fully in many other sources. Hence the guidance provided in the summary boxes gives headlines only rather than explaining in full the medical background.

Susan Quilliam, BA, MNLP

Freelance Writer, Broadcaster and Agony Aunt, Cambridge, UK.

E-mail:susan@susanquilliam.com

\section{References}

Quilliam S. Sex during pregnancy: Yes, Yes, Yes $J$ Fam Plann Reprod Health Care 2010; 36: 97-98. Young S. Safe sex during pregnancy (Letter). J Fam Plann Reprod Health Care 2010; 36: 180

\section{e-SRH e-Learning}

As an Instructing Doctor for the Faculty of Sexual and Reproductive Health Care (FSRH), I have enjoyed completing this online training ${ }^{1}$ at www.e-lfh.org.uk.

This is an excellent course, and the animations, including the physiology of the 
menstrual cycle, convey concepts more dynamically than could ever be displayed on paper.

Video consultations demonstrate communication aspects powerfully. The introductory emphasis on the law, the client perspective and young people places contraception and sexual health within its psychosocial context. Links to referenced sites are well chosen and accessible. The interactive self-assessment is challenging and - dare I say fun, and I learned from some errors but I will not confess where!

I think e-SRH e-Learning is good preparation for the Practical Sessions of the FSRH Diploma, ${ }^{2}$ and with regular updating it will remain a valuable educational resource for us all in the future. Congratulations to all the team involved with this project.

Michael Tapley, MBBS, DFFP

Associate Specialist, Contraception and Sexual Health,ChoicesCentre@Town Central,

Stockport, UK.

E-mail: m.tapley@btopenworld.com

References

e-Learning for Healthcare. www.e-lfh.org.uk

[Accessed 4 April 2010].

Faculty of Sexual and Reproductive Healthcare

Diploma. www.fsrh.org [Accessed 4 April 2010].

\section{Query about Faculty updated UKMEC}

I would be grateful if the Faculty of Sexual and Reproductive Healthcare could explain why in the updated UK Medical Eligibility Criteria for Contraceptive Use (UKMEC 2009) $)^{1}$ the Category 4 for body mass index (BMI) $>40$, has been removed? As a raised BMI is so closely associated with increased risk of venous thromboembolism, this does not seem logical. Without the Category 4 status, I am concerned that increasing numbers of patients with a BMI $>35$ and indeed a $\mathrm{BMI}>40$, will start, or continue to take, the combined pill, without any robust guidance to support this as a dangerous practice.

I am, however, pleased to see the Category $3 / 4$ for multiple risk factors for cardiovascular disease is now clearly stated. I would, however, prefer the definition for 'older age' to be stated. I would interpret this as being aged 35 years or over, but the additional comments at the end of the section imply the definition is aged 40 or above.

I fully appreciate that UKMEC is a guidance document and not a list of rules as such, but if these are too loosely presented then they will not serve their purpose in ensuring safe prescribing practice.

\section{Deborah J Lee, MFFP, MRCGP}

Associate Specialist in Reproductive Health,

Lead Clinician CASH, Salisbury Department of

Sexual Health, Salisbury, UK

E-mail:Deborah.J.Lee@salisbury.nhs.uk

\section{Reference}

Faculty of Sexual and Reproductive Healthcare. UK Medical Eligibility Criteria for Contraceptive Use UKMEC 2009). 2009. http://www.fsrh.org/admin/ uploads/UKMEC2009.pdf [Accessed 10 March 2010].

\section{Reply}

In her letter, ${ }^{1}$ Dr Lee raises a pertinent question regarding the new UK Medical Eligibility Criteria for Contraceptive Use (UKMEC 2009)2 categories for body weight and combined hormonal contraception (CHC) use. The current Clinical Effectiveness Unit was not involved in updating UKMEC but we believe the body weight categories were made less restrictive to make them more consistent with the categories for other cardiovascular risk factors and $\mathrm{CHC}$.
The rationale for these changes is partly explained in an article by Trussell et al. ${ }^{3}$ Obesity is generally perceived to be an important risk factor in $\mathrm{CHC}$ users because of the high relative risk of venous thromboembolism (VTE). Trussell argues that, in terms of absolute or attributable risk, other cardiovascular risk factors are more strongly associated with VTE and mortality than obesity. For instance, the absolute risk of VTE in CHC users aged 45-49 years (UKMEC 2) is 175 per 100000 , which is greater than a VTE risk of 105 per 100000 associated with $\mathrm{CHC}$ use and body mass index $(\mathrm{BMI}) \geq 35$ (UKMEC 3 ). The risks in terms of deaths in $\mathrm{CHC}$ users are even lower, with an absolute risk of 3.3 deaths per 100000 in smokers aged $<35$ years (UKMEC 2) and a risk of 2.4 per 100000 in women with $\mathrm{BMI} \geq 35$ (UKMEC 3 ).

With regard to the UKMEC 2009 section on multiple risk factors for cardiovascular disease, the text is unchanged from UKMEC 2005. The additional comments do appear to imply that the UKMEC definition of 'older age' is aged 40 years or above. Risk factors such as age are a continuum and there is not necessarily an exact cut-off. As Dr Lee acknowledges, UKMEC is only a guidance document, and it would be entirely appropriate for clinicians to apply their own clinical judgement.

Louise Melvin, MRCOG, MFSRH

Director, FSRH Clinical Effectiveness Unit, and Consultant in Sexual and Reproductive Health, Sandyford, Glasgow, UK.

E-mail:louise.melvin@nhs.net

References

Lee DJ. Query about updated UKMEC (Letter). J Fam Plann Reprod Health Care 2010; 36: 181

2 Faculty of Sexual and Reproductive Healthcare. UK Medical Eligibility Criteria for Contraceptive Us (UKMEC 2009). 2009. http://www.fsrh.org/admi / uploads/UKMEC2009.pdf [Accessed 10 March 2010]

3 Trussell J, Guthrie K, Schwarz EB. Much ado about little: obesity, combined hormonal contraceptive use and venous thrombosis. Contraception 2008; 77 : 143-146.

\section{Implanon ${ }^{\circledR}$ failure in patients on antiretroviral medication: the importance of disclosure}

We would like to draw other practitioners attention to a problem we have observed recently in our clinic, namely Implanon ${ }^{\circledR}$ failure in two women on antiretroviral (ARV) medication who failed to mention Implanon use to their HIV physicians. These women highlight the need for disclosure of HIV diagnosis to physicians offering contraceptive choices and Implanon use to the HIV physicians.

A 33-year-old woman, para 3, attended in May 2007, requesting termination of pregnancy. She had an Implanon since July 2004 and was amenorrhoeic until February 2007. She was commenced on Sustiva ${ }^{\circledR}$ (efavirenz $600 \mathrm{mg}$ tab) and Truvada ${ }^{\circledR}$ (emtricitabine $200 \mathrm{mg}$ and tenofovir disoproxil $245 \mathrm{mg}$ ) in January 2007 as her HIV viral load was rising. She was not asked and did not volunteer Implanon use. Concerns for the adverse effect of the ARVs on the fetus had prompted the termination request. After a norma dating ultrasound scan her decision to terminate became ambivalent. She became committed to the pregnancy after a normal 15-week scan an delivered a male baby weighing $3520 \mathrm{~g}$ at term.

A 35-year-old woman, para 1, conceived with an Implanon when commenced on efavirenz and lopinavir. She did not mention Implanon use to the HIV physician, and the contraceptive clinic had no record of her HIV status. She did not appreciate that Implanon was a drug that might interact with ARVs. She had amenorrhoea on the Implanon and did not realise she was pregnant until 19 weeks. After counselling she opted for a mid-trimester termination.

The concentration of contraceptive hormones may change by concomitant drug use and vice versa. It is good practice to enquire about current and previous drug use (specifically liver enzyme-inducers) when offering hormonal contraceptives ${ }^{1}$ Women should be advised that some drugs might reduce hormonal contraceptive effectiveness. With the exception of the progesterone-only injectable or the levonorgestrel intrauterine system, the contraceptive efficacy of hormonal methods is reduced by liver enzyme inducers. ${ }^{1}$

Some ARVs, such as protease inhibitors (amprenavir, atazanavir, nelfinavir, lopinavir, saquinavir, ritonavir) and non-nucleoside reverse transcriptase inhibitors (efavirenz, nevarapine), are metabolised by the CYP3A4 liver enzyme system and can affect liver enzymes. ${ }^{1}$

Each Implanon contains $68 \mathrm{mg}$ etonogestrel (ENG). The subdermal delivery method makes it $100 \%$ bioavailable. Serum ENG concentrations increase rapidly within 8 hours of insertion and peak after 4 days. $^{2}$ The release rate is $60-70$ $\mu \mathrm{g} /$ day in weeks 5-6 post-insertion, and decreases to $35-45 \mu \mathrm{g} /$ day at the end of the first year, to 30-40 $\mathrm{ug} / \mathrm{day}$ at the end of the second year, and then falls to $25-30 \mu \mathrm{g} /$ day at the end of the third year. ${ }^{2,3}$ These low concentrations are sufficient to inhibit ovulation for 3 years ${ }^{3}$

The advice for using the progesterone-only implant for women on long-term liver enzymeinducing drugs is to continue using it together with additional contraceptive protection (such as condoms) and for 4 weeks after the drugs are stopped. ${ }^{1}$

These cases highlight the unforeseen consequences of non-disclosure of HIV for both patients and physicians. One of the dilemmas facing physicians is whether to disclose the HIV diagnosis to general practitioners (GPs). Arguments have been advanced for specialists breaching confidentiality and notifying the GP against patients' wishes in the interest of normal medical practice, the patients' and health personnel best interests, and the interests of society in general. Gillon 4 examines each argument and concludes that none is sufficient to justify violating physician patient confidentiality in most cases.

Early contraceptive failure of Implanon in a woman on antiretroviral medication has been described ${ }^{5}$ The patient in the case report had an ectopic pregnancy.

The great majority of HIV-positive women are of reproductive age. Contraceptive options must take into account the risk of an unintended pregnancy, vertical transmission, and horizontal transmission for a non-infected partner. To achieve all these goals, a combined contraceptive (barrier method plus another method) is the 'gold standard'. Some practitioners will argue that the 'Double DUTCH' advice should be given to all patients and not just HIV-positive women.

Nisha Lakhi, MD

Medical Student, Department of Obstetrics and Gynaecology, Brooklyn Hospital Center, Brooklyn, New York, NY, USA.

E-mail:nlakhi@yahoo.com

Abha Govind, MFSRH, FRCOG

Consultant, Department of Obstetrics and Gynaecology, North Middlesex University Hospital, Edmonton, London, UK. E-mail: Abha.Govind@nmh.nhs.uk

1 Faculty of Family Planning and Reproductive Health (April 2005). Drug interactions with hormonce Cormonal 31: 139-151. Bennink HJ. The pharmacokinetics and pharmacodynamics of Implanon, a single-rod etonogestrel contraceptive implant. Eur J Contracept Reprod Health Care 2000; 5(Suppl. 2): 12-20. Reprod Health Care 2000; 5(Suppl. 2): 12-20.
Croxatto HB, Mäkäräinen L. The pharmacodynamics Croxatto HB, Makaarainen $L$. The pharmacodynamics Contraception 1998; 58(6 Suppl.): 91 S-97S. 